\title{
EFFECTS OF BODY MOVEMENT ON THE RELIABILITY OF A PORTABLE GAS ANALYSIS SYSTEM
}

doi: 10.2478/humo-2013-0008

\section{DANIEL J. KEEFER}

Millersville University, Millersville, USA

\begin{abstract}
Purpose. The purpose of this investigation was to determine the effect of body movement on the ability of a portable telemetric gas analysis device, the Cosmed $\mathrm{K}_{4} \mathrm{~b}^{2}$, to produce a reliable measure of walking oxygen consumption $\left(\mathrm{VO}_{2}\right)$. Methods. Thirteen adults were asked to report to a laboratory for three test sessions. During Session 1, participants were familiarized with the data collection procedures and completed a 15-min treadmill accommodation. In Sessions 2 and 3, each participant completed four 5 -min treadmill walking trials at $1.8 \mathrm{~m} \cdot \mathrm{sec}^{-1}$ under different experimental conditions while $\mathrm{VO}_{2}$ was collected using the portable system. The four conditions were used to manipulate the portable metabolic system to mimic different types of movement. Results. Data analysis revealed no significant differences $(p=0.070)$ amongst $\mathrm{VO}_{2}$ values across all four experimental conditions during Sessions 2 and 3. Between-day coefficients of variation for the mean $\mathrm{VO}_{2}$ values of the four conditions ranged from $2.7 \%$ to $3.8 \%$, with the highest level of variation occurring whilst the unit was strapped to the participant's chest. Conclusions. Viewed collectively, the Cosmed $\mathrm{K} \mathrm{b}^{2}$ may produce reliable measures of $\mathrm{VO}_{2}$ in adult participants during treadmill walking who exhibit little vertical oscillation. However, future research is necessary to determine if the $\mathrm{K}_{4} \mathrm{~b}^{2}$ is a valid instrument for collecting $\mathrm{VO}_{2}$ data if excessive body movement in the vertical direction can affect the data collection instrumentation.
\end{abstract}

Key words: oxygen cost, gait, outcome measurement

\section{Introduction}

The measurement of oxygen consumption $\left(\mathrm{VO}_{2}\right)$ is a valuable tool used to determine the amount of energy produced by an individual during physical activity. The 'gold standard' in determining $\mathrm{VO}_{2}$ is the Douglas bag method and has been used to determine the validity of other $\mathrm{VO}_{2}$ data collection systems [1]. Within the confines of this technique, expired air is collected into a Douglas bag and subsequently analyzed for $\mathrm{O}_{2}$ and $\mathrm{CO}_{2}$ content as well as the volume of air, which is then used to determine $\mathrm{VO}_{2}$. However, analyzing expired air for $\mathrm{VO}_{2}$ by this method is cumbersome and requires a researcher to undergo a lengthy training period. A simpler method for determining $\mathrm{VO}_{2}$ has been developed by using a computerized system (metabolic cart) to determine $\mathrm{VO}_{2}$. Nonetheless, because of its large size and immobility, the metabolic cart is a tool relegated to a laboratory setting. Portable versions of the metabolic cart were developed to allow researchers to determine the $\mathrm{VO}_{2}$ (a measure of energy expenditure) of any individual during all types of activities in any kind of setting.

These portable metabolic systems were shown to produce valid measurements of oxygen consumption compared to a metabolic cart by several researchers during treadmill locomotion [2-4] and cycle ergometry [1, 5, 6] in an adult population. Yet, these two forms of physical activity were conducted in a laboratory setting and involve motion that is quite stable, in which the body is largely immobile other than the legs. However, there is evidence within the research literature that shows the validity and reliability of portable gas analyzers can be questioned during more unstable movement patterns. For example, Duffield et al. [7] tested the validity of a portable gas analyzer against a computerized metabolic cart as well as the reliability of the portable system in different testing sessions conducted over a two day period for a 10-min jog, 3-min run and 1-min sprint using adult participants. The results found significant differences in $\mathrm{VO}_{2}$ measurements between the two metabolic collection systems during the 10min jog, 3-min run and 1-min sprint $(p<0.05)$ [7]. Furthermore, the authors did not find a significant between-day correlation when using the portable system with the 1-min sprint, which was the physical activity that involved the greatest level of effort [7].

In addition to the aforementioned validity studies, the questionable use of these portable metabolic systems during unstable movement can also be found in studies investigating children with cerebral palsy (CP). In many studies investigating the energy expenditure of children with CP during ambulation, researchers asked participants to walk around a course of a certain distance (i.e. overground walking) while $\mathrm{VO}_{2}$ was collected using a portable gas exchange system. However, no studies to date have tested the validity of using a portable metabolic system in children with a disability or even healthy children. In 1996, Corry et al. [8] assessed the repeatability (not validity) of a portable metabolic cart to be $13 \%$ of the mean $\mathrm{VO}_{2}$ values 
produced across three speeds in a group of ten children with a disability. Similarly, Bowen et al. [9] demonstrated a $17.5 \%$ variability rate in $\mathrm{VO}_{2}$ for children with CP between measurements taken on different days using a portable metabolic system. However, a study by Keefer et al. [10] showed only an $8 \%$ variability rate in between-day $\mathrm{VO}_{2}$ when using the 'gold standard' Douglas bag method in children with CP. An explanation for this large difference between Bowen et al. [9] and Keefer et al. [10] could be that the instrumentation of the portable metabolic system is affected by the irregular gait performance [11] seen in the walking pattern of children with CP. Viewed in concert, there is data to show that portable metabolic systems may not be able to measure $\mathrm{VO}_{2}$ on a consistent basis during ambulation that involves more pronounced body movement. Therefore, the purpose of this investigation was to determine the effect of body movement on the ability of a portable gas exchange device to produce a reliable measure of walking oxygen consumption.

\section{Material and methods}

Thirteen able-bodied adults (ten males, three females; mean age $35.0 \pm 9.5 \mathrm{yrs}$; mean weight $79.1 \pm 11.5 \mathrm{~kg}$; mean height $178.2 \pm 6.3 \mathrm{~cm}$ ) participated in this investigation. Adult participants were used because the portable gas exchange device has only been validated in an adult population [1-5]. Prior to participation, all volunteers signed an informed consent form that was approved by the University's Institutional Review Board for the use of human subjects. All procedures were followed in accordance to the Helsinki Declaration [12]. Each participant reported to the laboratory on three separate occasions and was instructed to not eat or drink at least two hours prior to testing as well as not ingest caffeine on that day. During their initial visit (Session 1), the participants were familiarized with the data collection tools and completed a 15 -min treadmill accommodation period at $1.8 \mathrm{~m} \cdot \mathrm{sec}^{-1}$ while wearing a facemask and portable metabolic system, the Cosmed $\mathrm{K}^{4} \mathrm{~b}^{2}$ (Cosmed, Italy).

The subsequent two testing sessions (Sessions 2 and 3) were identical and involved each participant completing four 5 -min treadmill walking trials at $1.8 \mathrm{~m} \cdot \mathrm{sec}^{-1}$ under different experimental conditions. The order of each trial was randomly selected in each session and the walking trials were interspersed with five min of rest. The four experimental trials included (a) walking with the portable device worn on the body using a harness; (b) walking with the portable device off the body and set aside on a stable surface; (c) walking with the portable device off the body and placed in a specially constructed mechanism designed to tilt the device between $90^{\circ}$ (simulating the upright, vertical position when walking) and $60^{\circ}$ (simulating the forward bending action when walking); and (d) walking with the portable device off the body and placed in a specially constructed mechanism designed to vertically oscillate the device between 0 and $6.25 \mathrm{~cm}$ in height (simulating the vertical oscillation that occurs to an individual's center of gravity when walking). When the Cosmed unit was not worn, a weight equal to the device was used as a substitute on the harness. For conditions (c) and (d), the portable unit was moved in the respective direction using a cadence equivalent to the participant's step frequency. In addition, when securing the $\mathrm{K} \mathrm{b}^{2}$ to the devices to complete the movements under conditions (c) and (d), care was taken to ensure that the unit was not impeded from functioning. The range of movement in conditions (c) and (d) were chosen to exacerbate the possible movements of the body during crouch gait, as observed in children with CP when walking $[13,14]$.

During all the test conditions in Sessions 2 and 3, gross $\mathrm{VO}_{2}$ was measured using the portable system over each 5-min trial. Prior to each session, the Cosmed system was calibrated for gas composition using primary standard gases $\left(16.00 \% \mathrm{O}_{2}\right.$ and $\left.4.00 \% \mathrm{CO}_{2}\right)$ and for volume using a three liter syringe. Before the walking conditions were started, participants were first weighed on a Health-o-meter balance scale. The participants were then fitted with the Cosmed facemask as per the manufacturer's instructions, which was secured to the participant using a head-cap assembly. The straps on the side of the head-cap assembly were pulled tight and the mask was subsequently tested for leaks to ensure that all expired air was measured by the Cosmed system. Once each trial began, a researcher initiated the measurement system to begin collecting $\mathrm{VO}_{2}$ data. However, only the final two minutes of $\mathrm{VO}_{2}$ data for each walking trial was used for statistical analysis to allow for a steadystate $\mathrm{VO}_{2}$ value to be achieved.

The stability of $\mathrm{VO}_{2}$ was quantified by performing repeated-measures three-factor analyses of variance (ANOVA) on the metabolic data obtained during the four trials of Session 2 and again using the $\mathrm{VO}_{2}$ values from Session 3. The three factors were Condition (on the body, off the body, tilted and vertically oscillated), Trial Order (one thru four), and Day (Sessions 2 and 3). To determine between-day stability in energy cost, between-day coefficient of variation $(\mathrm{CV})$ values were derived for measures of $\mathrm{VO}_{2}$ with each experimental condition. For each participant, $\mathrm{CV}$ values were calculated from the average $\mathrm{VO}_{2}$ value for each of the experimental conditions from Sessions 2 and 3. These individual CV values were then averaged across the participants to yield a mean group between-day CV value for each experimental condition. To further characterize between-day variability, a measure of daily variability was determined for each experimental condition using the calculation provided by Bowen et al. [9]. Statistical significance was established at $p<0.05$. 
Table 1. Average $( \pm \mathrm{SD})$ walking

$\mathrm{VO}_{2}$ values $\left(\mathrm{ml} \cdot \mathrm{kg}^{-1} \cdot \mathrm{min}^{-1}\right)$ for the four experimental conditions tested in Sessions 2 and 3

\begin{tabular}{ccccc}
\hline \multirow{2}{*}{ Session } & \multicolumn{5}{c}{ Condition } \\
\cline { 2 - 5 } & $\mathrm{a}$ & $\mathrm{b}$ & $\mathrm{c}$ & $\mathrm{d}$ \\
\hline 2 & $18.9(1.1)$ & $18.7(1.2)$ & $18.7(1.3)$ & $19.3(2.3)$ \\
3 & $18.7(1.5)$ & $18.5(1.4)$ & $18.8(1.5)$ & $19.1(1.6)$ \\
\hline
\end{tabular}

$\mathrm{a}$ - on the body; b - off the body; c - tilted;

$\mathrm{d}$ - vertically oscillated

four experimental conditions not statistically different $(p>0.05)$ from each other across each session and for each condition between sessions

Table 2. Between-day coefficients of variation (\%) for the mean $\mathrm{VO}_{2}$ values of the four conditions

\begin{tabular}{cccc}
\hline \multicolumn{5}{c}{ Condition } \\
\hline $\mathrm{a}$ & $\mathrm{b}$ & $\mathrm{c}$ & $\mathrm{d}$ \\
\hline 3.8 & 2.7 & 3.0 & 3.2 \\
\hline
\end{tabular}

a - on the body; b - off the body; c - tilted;

$\mathrm{d}$ - vertically oscillated

Table 3. Daily variability (\%) for the mean $\mathrm{VO}_{2}$ values of the four conditions

\begin{tabular}{cccc}
\hline \multicolumn{5}{c}{ Condition } \\
\hline $\mathrm{a}$ & $\mathrm{b}$ & $\mathrm{c}$ & $\mathrm{d}$ \\
\hline 5.3 & 3.8 & 4.2 & 4.5 \\
\hline
\end{tabular}

$\mathrm{a}$ - on the body; $\mathrm{b}$ - resting off the body; c - tilted; $\mathrm{d}$ - vertically oscillated

\section{Results}

Repeated measures analysis revealed no significant differences $(p>0.05)$ amongst $\mathrm{VO}_{2}$ values for the three factors of Day $(p=0.371)$, Trial Order $(p=0.901)$ and Condition $\left(p=0.070\right.$ ). Table 1 displays the $\mathrm{VO}_{2}$ data from the four different conditions in Sessions 2 and 3. Betweenday coefficients of variation $(\mathrm{CV})$ for the mean $\mathrm{VO}_{2}$ values of the four conditions ranged from $2.7 \%$ to $3.8 \%$ (Tab. 2). Moreover, no significant differences were determined between the measures of daily variability in $\mathrm{VO}_{2}$ values for the four conditions, which ranged from $3.8 \%$ to $5.3 \%$ (Tab. 3 ).

\section{Discussion}

The results from this investigation demonstrate that no significant difference $(p=0.07)$ could be detected when using the portable gas analysis system under different experimental conditions designed to mimic excessive body movements. However, a possible trend does appear to exist for these conditions, wherein the $\mathrm{VO}_{2}$ values for the vertically oscillating condition (d) were higher in both Session 2 and 3 compared to the other conditions. For this experiment, a higher level of significance may have been achieved with either more participants or a greater vertical movement of the Cosmed unit. Power analysis of the current data revealed that in order to achieve a $p=0.05$ significance level when comparing the stationary to the vertically oscillating condition, 37 participants would be necessary with a Beta error level at 50\%. Evidence in the available literature may already exist in demonstrating that moving the $\mathrm{K}_{4} \mathrm{~b}^{2}$ to a greater degree in the vertical position could also affect the measurement capability of the portable unit. In the previously mentioned study by Duffield et al. [7], the sprint trial was the only activity that did not produce a significant between-day correlation, whereas the walking and jogging trials did. This could have been a result of a higher level of vertical oscillation of the center of mass during sprinting when compared to the other modalities. In an investigation by Williams and Cavanagh [15], trained runners were found to elevate their center of mass by $9.2 \mathrm{~cm}$ in the vertical direction while running at $3.6 \mathrm{~m} \cdot \mathrm{sec}^{-1}$. This value is greater than the $6.25 \mathrm{~cm}$ used in this study to vertically move the $\mathrm{K}_{4} \mathrm{~b}^{2}$. Therefore, more research is warranted in order to determine if the Cosmed unit is affected by more pronounced vertical movement.

Within the pediatric literature, a paucity of data exist detailing the average amount of vertical oscillation produced by a child with CP during walking. One study by Bennett et al. [16] stated that children with CP (mean age $9.7 \mathrm{yrs}$ ) had a $60 \%$ higher level of vertical oscillation of their center of mass compared to able-bodied controls. However, the authors did not provide any raw data for the vertical movement measures. According to Dierick et al. [17], the average vertical movement of the center of mass for able-bodied children at a slightly younger age (7-9 yrs) than in Bennett et al.'s study was $3.5 \mathrm{~cm}$ during walking [16]. Therefore, a value that is $60 \%$ greater than the vertical displacement measured by Dierick et al. [17] would be $5.6 \mathrm{~cm}$, which is less than the $6.25 \mathrm{~cm}$ used in this investigation. With this in mind, the $\mathrm{K}^{2} \mathrm{~b}^{2}$ could be used to determine oxygen consumption values during walking in children with $\mathrm{CP}$ if the Cosmed device was validated for children. However, if an intervention aimed at improving the gait function of children with $\mathrm{CP}$ produces different post-intervention vertical movement during walking compared to the pre-intervention session, then any difference in oxygen consumption could be attributed to the data collection device. Therefore, to eliminate this possibility, the $\mathrm{K}^{2} \mathrm{~b}^{2}$ needs to be scrutinized by further research.

In the current investigation, low between-day $\mathrm{CV}$ $(3.8 \%)$ and daily variability $(5.3 \%)$ values suggest that, when worn on the body, this portable gas analysis unit can provide a reliable measure of $\mathrm{VO}_{2}$ in an adult population while walking on a treadmill. Fairly low daily variability values in $\mathrm{VO}_{2}(8.8 \%)$ have also been obtained 
from children with hemiplegic CP while walking on a treadmill using the Douglas bag method [10]. However, higher values of daily variability in $\mathrm{VO}_{2}(17.5 \%)$ were determined by Bowen et al. [9] in children with CP (four with diplegia and one with hemiplegia) when walking around a course of a certain distance using a portable metabolic system by Cosmed. One explanation for the high variability rate determined by Bowen et al. [9] could be that four of the five children had diplegic CP. Keefer et al. [10] believes that children with two affected limbs during walking may have a greater level of daily variability compared to those with only one affected limb. Notwithstanding, another explanation for the higher daily variability level measured by Bowen et al. [9] could be attributed to the fact that the portable metabolic device has not yet been validated in youth, as was mentioned previously. In a another study by Keefer et al. [18], three children with hemiplegic CP and one with diplegia were found to have a daily variability value of $8 \%$ in oxygen consumption during overground walking using the Douglas bag method. This fairly low daily variability value was obtained even though a child with diplegic CP was included in the analysis and the mean value during overground walking was similar to the level obtained $(8.8 \%)$ when treadmill walking in a population that had only hemiplegic CP [10]. These results suggest that the portable metabolic unit could be a limiting factor when trying to obtain oxygen consumption measures from children with CP.

\section{Conclusion}

Viewed in concert, reliable measures of $\mathrm{VO}_{2}$ can be obtained from adult participants during treadmill walking by the Cosmed $\mathrm{K}_{4} \mathrm{~b}^{2}$ if the vertical oscillation of the portable unit is kept to a minimum. However, future research is necessary to determine if excessive body movement in the vertical direction can affect data collection in this portable metabolic system and if the $\mathrm{K} 4 \mathrm{~b}^{2}$ can be used to determine oxygen consumption in both able-bodied children and children with a disability. Knowing if this portable device is valid and reliable is crucial to therapists, orthopedists and researchers who wish to determine if an intervention, aimed at improving gait function through lower oxygen cost during walking, is successful.

\section{Acknowledgments}

This research was funded in part by the Pennsylvania State System Faculty Professional Development Council Annual Grant Program.

\section{References}

1. Brehm M.-A., Harlaar J., Groepenhof H., Validation of the portable VmaxST system for oxygen-uptake measurement. Gait Posture, 2004, 20 (1), 67-73, doi: 10.1016/S09666362(03)00097-3.
2. Eisenmann J.C., Brisko N., Shadrick D., Welsh S., Comparative analysis of the Cosmed Quark $\mathrm{b}^{2}$ and the $\mathrm{K}_{4} \mathrm{~b}^{2}$ gas analysis systems during submaximal exercise. J Sports Med Phys Fitness, 2003, 43 (2), 150-155.

3. Lucia A., Fleck S.J., Gotshall R.W., Kearney J.T., Validity and reliability of the Cosmed K2 instrument. Int J Sports Med,1993,14(7),380-386,doi:10.1055/s-2007-1021196.

4. Maiolo C., Melchiorri G., Iacopino L., Masala S., De Lorenzo A., Physical activity energy expenditure measured using a portable telemetric device in comparison with a mass spectrometer. Br J Sports Med, 2003, 37 (5), 445447, doi:10.1136/bjsm.37.5.445.

5. Hausswirth C., Bigard A.X., Le Chevalier J.M., The Cosmed K4 telemetry system as an accurate device for oxygen uptake measurements during exercise. Int J Sports Med, 1997, 18 (6), 449-453, doi: 10.1055/s-2007-972662.

6. McLaughlin J.E., King G.A., Howley E.T., Bassett Jr D.R., Ainsworth B.E., Validation of the Cosmed $\mathrm{K} 4 \mathrm{~b}^{2}$ portable metabolic system. Int J Sports Med, 2001, 22 (4), 280-284, doi: 10.1055/s-2001-13816.

7. Duffield R., Dawson B., Pinnington H.C., Wong P., Accuracy and reliability of a Cosmed $\mathrm{K}_{4} \mathrm{~b}^{2}$ portable gas analysis system. J Sci Med Sport, 2004, 7 (1), 11-22, doi: 10.1016/ S1440-2440(04)80039-2

8. Corry I.S., Duffy C.M., Cosgrave A.P, Graham H.K., Measurement of oxygen consumption in disabled children by the Cosmed K2 portable telemetry system. Dev Med Child Neurol, 1996, 38 (7), 585-593, doi: 10.1111/j.14698749.1996.tb12123.x.

9. Bowen T.R., Lennon N., Castagno P., Miller F., Richards J., Variability of energy-consumption measures in children with cerebral palsy. J Pediatr Orthop, 1998, 18 (6), 738-742.

10. Keefer D.J., Tseh W., Caputo J.L., Apperson K., McGreal S., Morgan D.W., Within- and between-day stability of treadmill walking $\mathrm{VO}_{2}$ in children with hemiplegic cerebral palsy: Stability of walking $\mathrm{VO}_{2}$ in children with CP. Gait Posture, 2005, 21 (1), 80-84, doi: 10.1016/j.gaitpost.2004. 01.004.

11. Bar-Or O., Pediatric Sports Medicine for the Practitioner: From Physiologic Principles to Clinical Applications. Springer, New York 1983, 376.

12. Harris D.J., Atkinson G., International Journal of Sports Medicine - Ethical Standards in Sport and Exercise Science Research. Int J Sports Med, 2009, 30 (10), 701-702, doi: 10.1055/s-0029-1237378

13. Hicks J.L., Schwartz M.H., Arnold A.S., Delp S.L., Crouched postures reduce the capacity of muscles to extend the hip and knee during the single limb stance phase of gait. J Biomech, 2008, 41 (5), 960-967, doi: 10.1016/j.jbiomech. 2008.01.002.

14. Sutherland D.H., Davids J.R., Common gait abnormalities of the knee in cerebral palsy. Clin Orthop Relat Res, 1992, 288, 139-147.

15. Williams K.R., Cavanagh P.R., Relationship between distance running mechanics, running economy, and performance. J Appl Phys, 1987, 63 (3), 1236-1245.

16. Bennett B.C., Abel M.F., Wolovick A., Franklin T., Allaire P.E., Kerrigan D.C., Center of mass movement and energy transfer during walking in children with cerebral palsy. Arch Phys Med Rehabil, 2005, 86 (11), 2189 2194, doi: 10.1016/j.apmr.2005.05.012. 


\section{HUMAN MOVEMENT}

D.J. Keefer, Reliability of gas analysis system

17. Dierick F., Lefebvre C., van den Hecke A., Detrembleur C., Development of displacement of centre of mass during independent walking in children. Dev Med Child Neurol,2004,46(8),533-539, doi:10.1111/j.1469-8749.2004. tb01011.x.

18. Keefer D.J., Morgan D.W., Caputo J.L., Tseh W., Effect of a heel-loaded auditory feedback system on walking economy and gait speed in children with cerebral palsy: a preliminary study. Proceedings of the American Academy for Cerebral Palsy and Developmental Medicine, September 1999, Washington, DC.

Paper received by the Editors: September 14, 2012 Paper accepted for publication: January 25, 2013

\section{Correspondence address}

Daniel J. Keefer

113 Pucillo Gymnasium

Department of Wellness and Sport Sciences

Millersville University

Millersville, PA 17551, USA

e-mail: dkeefer@millersville.edu 